\title{
Thermal System Simulation Study of Wide-Load Out-Of-Stock Technical Transformation to Reduce SCR Inlet Flue Gas Temperature of 300MW Subcritical Boiler
}

\author{
Tao QIN, Jun RONG ${ }^{1}$, Guang YANG, Yankai WANG, Yi HAN, Bin CAI, Yingli YU \\ Inner Mongolia Electric Power Science and Research Institute, Hohhot 010020, Inner \\ Mongolia, China
}

\begin{abstract}
During the operation of a 300MW subcritical boiler of a power plant, there is a low temperature of the SCR inlet flue gas under medium and low load conditions. In order to effectively solve the problem of low SCR inlet temperature under low load conditions, and improve the adaptability of the coal type. Three kinds of wide load denitration technology reform schemes are proposed. With the boiler thermal system simulation software BESS, the thermal calculations of the three transformation schemes were carried out. The results show that: the Scheme C is the optimal solution. After the transformation, the temperature of the SCR inlet flue gas increased by $21^{\circ} \mathrm{C}$ under the ultra-low load condition, and the exhaust gas temperature increased by about $7^{\circ} \mathrm{C}$. At the same time, the possible impacts of the reform of the Scheme $\mathrm{C}$ and the key issues that need to be paid attention to during the transformation process are evaluated and discussed.
\end{abstract}

Keywords. 300MW subcritical boiler, SCR inlet flue gas temperature, wide-load denitrification technology transformation, thermal system simulation

\section{Introduction}

At present, China's coal-fired boilers generally use the SCR process for flue gas denitrification treatment. For coal-fired boilers that use SCR denitrification, the SCR inlet flue gas temperature will decrease as the unit load decreases. The denitration system catalyst requires a flue gas temperature of $300 \sim 400^{\circ} \mathrm{C}$. When some power station boilers have low load, the SCR system is forced to withdraw from operation due to the inlet flue gas temperature not meeting the operation requirements, this will cause a significant increase in the NOx emissions of the unit [1]. According to statistics, about $30 \%$ of coal-fired boilers in China have problems in the low-load conditions that the SCR system cannot be put into operation due to insufficient smoke temperature.

This paper selects a 300MW subcritical boiler in Inner Mongolia. Aiming at the low temperature of SCR inlet flue gas under low load, several kinds of wide-load denitration

${ }^{1}$ Corresponding author: Jun Rong, Inner Mongolia Electric Power Science and Research Institute, Hohhot 010020, Inner Mongolia, China; E-mail: rongjun123@126.com. 
transformation schemes are proposed without affecting the combustion of the furnace, the steam parameters and the stable operation of the medium and high load SCR system. The thermal calculation software BESS is used to calculate the thermal calculation of several schemes, analyze and compare the effects of different schemes, and determine the optimal scheme [2,3].

\section{Equipment Introduction}

The 300MW boiler is a model HG-1025/17.5-YM11 boiler designed and manufactured by Harbin Boiler Co., Ltd. according to the technology of American ABB-CE company. The boiler is a natural circulation single furnace, one intermediate reheating, balanced ventilation, single steam boiler. The boiler adopts a full steel frame suspension structure, a tight-closed П-type arrangement, and a solid-state slag discharge. The milling system is a positive pressure direct-blowing pulverizing system equipped with five HP863 medium-speed coal pulverizers produced by Shanghai Heavy Machinery Plant. Two three-point warehouse-type rotary air preheaters are arranged in the lower part of the rear shaft flue. The SCR denitrator reactor allows the flue gas inlet temperature to be between $300^{\circ} \mathrm{C}$ and $400^{\circ} \mathrm{C}$, the schematic layout of the boiler is shown in Figure 1.

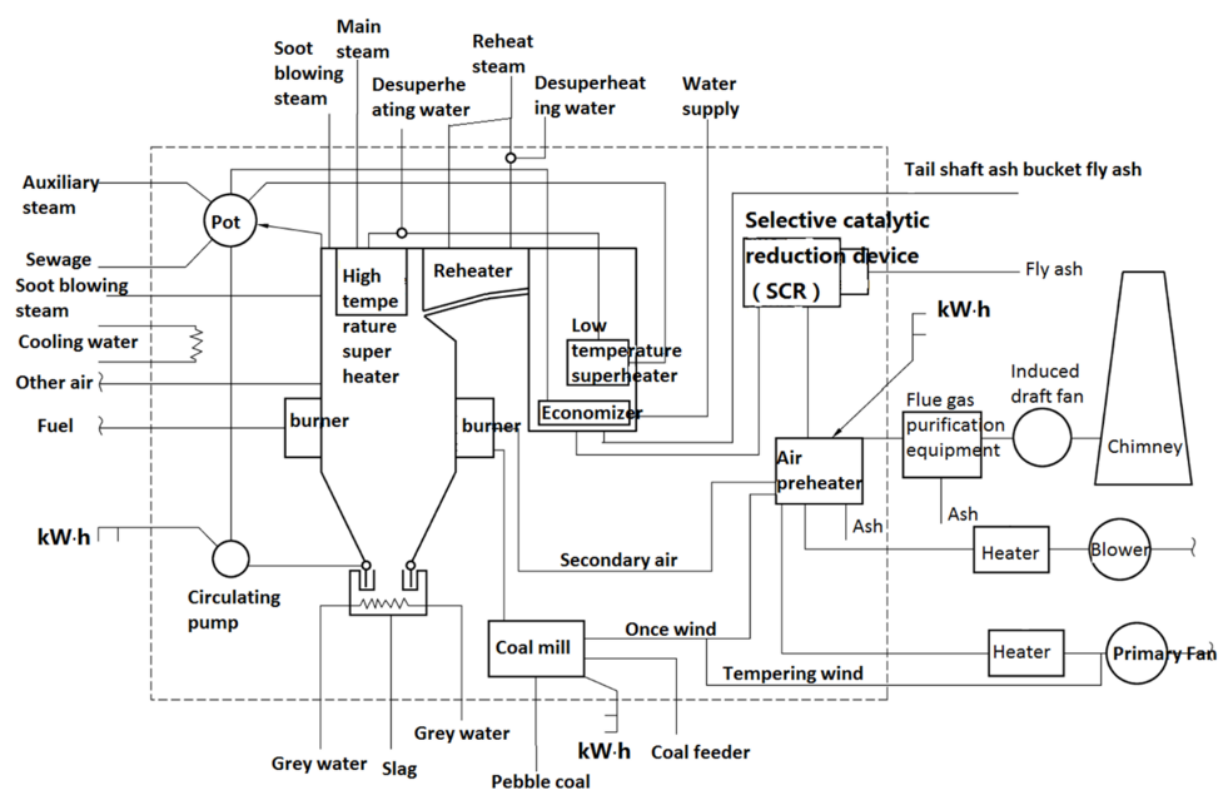

Figure 1. The schematic layout of the boiler. 


\section{Thermal Calculation Check and Wide Load Denitration Technology Transformation Plan}

\subsection{Thermal Calculation Check}

In order to ensure the reliability of the thermal calculation results, the thermal calculation of the thermal system simulation model is checked according to the actual operation parameters of the boiler, so as to ensure that the check calculation results are in good agreement with the actual operation data of the boiler, and the system model and parameters constructed by the thermal calculation are reliable and effective.

The field test data of $299.3 \mathrm{MW}, 209.7 \mathrm{MW}$ and $75 \mathrm{MW}$ are selected for thermal calculation and verification. The coal quality data in the test and the actual operation parameters of the boiler are shown in Table 1 and Table 2.

Table 1. Actual fuel characteristics.

\begin{tabular}{cccc}
\hline Item & $299.3 \mathrm{MW}$ & $\begin{array}{c}\text { Load conditions } \\
209.7 \mathrm{MW}\end{array}$ & $75 \mathrm{MW}$ \\
\hline Car (\%) & 45.32 & 46.97 & 48.82 \\
Har (\%) & 2.34 & 2.47 & 2.62 \\
Oar (\%) & 9.23 & 9.88 & 8.84 \\
Nar (\%) & 0.51 & 0.53 & 0.52 \\
Sar (\%) & 0.59 & 0.61 & 0.54 \\
Aar (\%) & 19.01 & 16.34 & 17.07 \\
Mar (\%) & 23 & 23.2 & 21.6 \\
Vdaf (\%) & 41.41 & 39.98 & 37.87 \\
Qnet,ar (kJ/kg) & 16310 & 17040 & 17457 \\
\hline
\end{tabular}

Table 2. Actual operating parameters of the boiler.

\begin{tabular}{cccc}
\hline Item & & Load conditions & \\
& $299.3 \mathrm{MW}$ & $209.7 \mathrm{MW}$ & $75 \mathrm{MW}$ \\
\hline Main steam flow $(\mathrm{t} / \mathrm{h})$ & 918.8 & 606.8 & 211.4 \\
Main steam pressure $(\mathrm{MPa})$ & 16.30 & 15.03 & 11.2 \\
Main steam temperature $\left({ }^{\circ} \mathrm{C}\right)$ & 540 & 541 & 514 \\
Reheat steam inlet pressure $(\mathrm{MPa})$ & 3.56 & 2.37 & 0.84 \\
Reheat steam inlet temperature $\left({ }^{\circ} \mathrm{C}\right)$ & 321.6 & 300.8 & 254 \\
Reheat steam outlet pressure $(\mathrm{MPa})$ & 3.36 & 2.25 & 0.83 \\
Reheat steam outlet temperature $\left({ }^{\circ} \mathrm{C}\right)$ & 543 & 540 & 483 \\
Boiler feed water temperature $\left({ }^{\circ} \mathrm{C}\right)$ & 270 & 247 & 196.6 \\
Boiler feed water pressure $(\mathrm{MPa})$ & 17.8 & 15.9 & 11.6 \\
Boiler feed water flow $(\mathrm{t} / \mathrm{h})$ & 913.1 & 619.8 & 228.0 \\
\hline
\end{tabular}

Under the load of 299.3MW, 209.7MW, and 75MW, the calibration calculations are carried out respectively, and the calculation results are compared with the actual operating data as shown in Table 3. Among them, the error between the main steam temperature and the actual operating temperature is less than $3^{\circ} \mathrm{C}$, the error between the reheated steam temperature and the actual operating data is less than $3{ }^{\circ} \mathrm{C}$, and the deviation between the economizer outlet temperature and the actual operating data is controlled within $5^{\circ} \mathrm{C}$, the deviation between the exhaust gas temperature and the actual operating data is controlled within $5^{\circ} \mathrm{C}$. The unit operating data is measured by on-site sensors, and there will be certain measurement errors. Therefore, the error of the thermal calibration calculation is within an acceptable range, the calculated model and system parameters of the thermal system are reliable and effective. It is worth noting that in the thermal calculation results under the $75 \mathrm{MW}$ working condition, there is a certain degree 
of under-temperature phenomenon in the outlet temperature of the superheated steam and the outlet temperature of the reheated steam. The inlet flue gas temperature of SCR is significantly lower than the allowable temperature of the denitrification device reactor, and it is in good agreement with the low-load stability test data of the unit, which once again proves the reliability of the established thermal system model.

Table 3. Comparison of calculation results and actual operating data under 299.3MW, 209.7MW, 75MW load.

\begin{tabular}{|c|c|c|c|c|c|c|c|c|c|}
\hline \multirow{3}{*}{ Item } & \multicolumn{9}{|c|}{ Actual operating load } \\
\hline & $299.3 \mathrm{M}$ & & & 209.7MV & & & $75 \mathrm{MW}$ & & \\
\hline & $\begin{array}{l}\text { Operating } \\
\text { parameters }\end{array}$ & $\begin{array}{l}\text { Simulation } \\
\text { results }\end{array}$ & Error & $\begin{array}{l}\text { Operating } \\
\text { parameters }\end{array}$ & $\begin{array}{l}\text { Simulation } \\
\text { results }\end{array}$ & Error & $\begin{array}{l}\text { Operating } \\
\text { parameters }\end{array}$ & $\begin{array}{l}\text { Simulation } \\
\text { results }\end{array}$ & Error \\
\hline $\begin{array}{c}\text { Superheated } \\
\text { steam outlet } \\
\text { temperature }\left({ }^{\circ} \mathrm{C}\right)\end{array}$ & 540 & 543 & 3 & 541 & 543 & 2 & 514 & 511 & -3 \\
\hline $\begin{array}{c}\text { Reheated } \\
\text { steam inlet } \\
\text { temperature }\left({ }^{\circ} \mathrm{C}\right)\end{array}$ & 321 & 321 & 0 & 300 & 300 & 0 & 254 & 254 & 0 \\
\hline $\begin{array}{c}\text { Reheated } \\
\text { steam outlet } \\
\text { temperature }\left({ }^{\circ} \mathrm{C}\right)\end{array}$ & 543 & 544 & 1 & 540 & 537 & -3 & 483 & 481 & -2 \\
\hline $\begin{array}{l}\text { Working fluid } \\
\text { temperature at the } \\
\text { inlet of the } \\
\text { economizer }\left({ }^{\circ} \mathrm{C}\right)\end{array}$ & 269 & 270 & 1 & 246 & 247 & 1 & 233 & 230 & -3 \\
\hline $\begin{array}{l}\text { Inlet flue gas } \\
\text { temperature of } \\
\text { SCR }\left({ }^{\circ} \mathrm{C}\right)\end{array}$ & 386 & 384 & -2 & 350 & 345 & -5 & 276 & 279 & 3 \\
\hline $\begin{array}{c}\text { Exhaust } \\
\text { temperature }\left({ }^{\circ} \mathrm{C}\right)\end{array}$ & 142 & 142 & 0 & 131 & 126 & -5 & 114 & 112 & -2 \\
\hline
\end{tabular}

\subsection{Technical Transformation Scheme of Wide Load Denitration}

With the decrease of the boiler load, the flue gas temperature at the outlet of the economizer will also decrease. When the load drops to a certain level, the flue gas temperature at the outlet of the economizer will be lower than $300^{\circ} \mathrm{C}$, which can not meet the reaction temperature of denitration, resulting in excessive NOx emission, catalyst deactivation, increased ammonia escape, etc. The wide load denitration technology is to increase the flue gas temperature at the outlet of economizer at low load to ensure the chemical reaction temperature of catalyst, so as to achieve the minimum technical output, stable denitration at full load and all time, and meet the requirements of clean emission [4].

In this paper, three feasible schemes have been selected after actual field tests and preliminary calculations. In scheme A, the bypass at the water side of economizer is adopted, and the regulating valve and connecting pipe are set in front of the header at the inlet of economizer to bypass part of the water supply, so as to reduce the heat absorption of water supply in economizer, and finally achieve the purpose of increasing the flue gas temperature at the outlet of economizer. Scheme B adopts the hierarchical economizer arrangement, which divides the economizer arranged in the boiler tail flue into two parts. The first part is still arranged in the boiler tail flue, with a heat transfer area of about $4030.91 \mathrm{~m} 2$. The second part is arranged behind the SCR reactor, with a heat transfer area of about $2015.45 \mathrm{~m} 2$. The economizer arranged in the boiler tail flue is called the primary economizer, the economizer in the lower part of SCR reactor can be called secondary economizer. Scheme B needs to add new supports and connecting pipes, change the flue after the existing SCR reactor, reinforce the flue, and check the denitration steel frame and foundation load. In addition, new soot blowing equipment, 
auxiliary structures and instruments are needed. In scheme $\mathrm{C}$, the flue gas bypass modification is adopted, and a hole is opened at the flue of the rear steering room to extract part of the high temperature flue gas to the SCR interface. Under low load, the flue gas temperature at the SCR inlet can reach the minimum ammonia injection temperature requirement by extracting the higher temperature flue gas and mixing the flue gas from the economizer outlet. Scheme $\mathrm{C}$ needs to increase the flue gas baffle, some steel structures and supports and hangers, and the bypass flue needs to be equipped with expansion joint, electric shut-off baffle and regulating baffle for flue gas flow and temperature regulation. Schemes $\mathrm{A}$ to $\mathrm{C}$ are shown in Figures 2 to 4 .

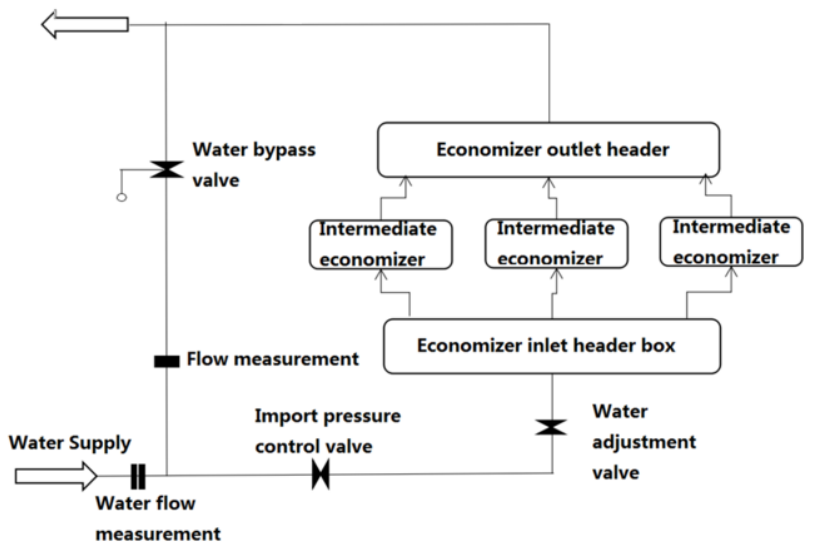

Figure 2. Scheme A, the water side economizer bypass arrangement.

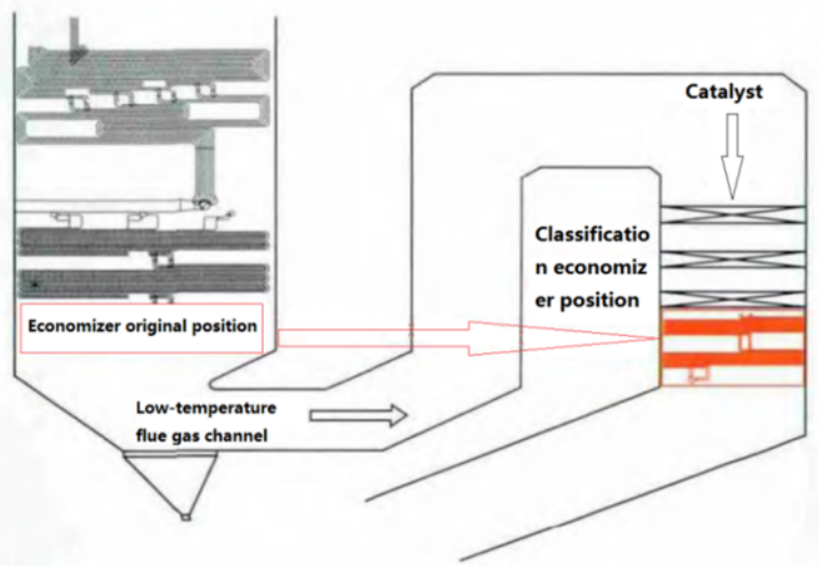

Figure 3. Scheme B, Classification economizer transformation. 


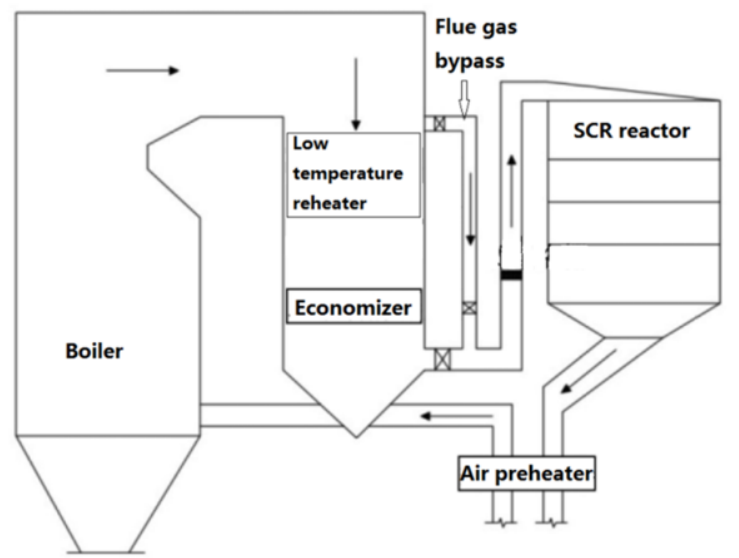

Figure 4. Program C, flue gas bypass transformation.

\section{Calculation Results and Comparison of Wide-Load Denitrification Technology Transformation Schemes}

Under the $25 \%$ rated load condition, the calculation data of the thermal system after the three transformation schemes and before the transformation are compared and analyzed, as shown in Table 4.

Through calculation and analysis, after scheme A water bypass transformation, under $25 \%$ rated load condition, in order to make SCR inlet flue gas temperature reach the allowable temperature of denitration device reactor (above $300^{\circ} \mathrm{C}$ ), the water side bypass flow should reach more than $79 \%$ of the total flow. At this time, the flue gas temperature at $\mathrm{SCR}$ inlet rises to $301.15^{\circ} \mathrm{C}$, the flue gas temperature of boiler rises from $112^{\circ} \mathrm{C}$ to $120^{\circ} \mathrm{C}$, the boiler efficiency decreases from $93.72 \%$ to $93.29 \%$, and the working medium temperature at economizer outlet rises to $302^{\circ} \mathrm{C}$, reaching the boiling point temperature. After using scheme B to retrofit the staged economizer, under the condition of $25 \%$ rated load, the flue gas temperature at SCR inlet is $302.618^{\circ} \mathrm{C}$, the flue gas temperature of boiler is $112.832^{\circ} \mathrm{C}$, and the boiler efficiency is $93.715 \%$. After retrofitting the flue gas bypass with scheme $\mathrm{C}$, under the condition of $25 \%$ rated load, when the bypass flue gas flow is greater than $19 \%$, the flue gas temperature at SCR inlet can be higher than $300^{\circ} \mathrm{C}$, which can meet the temperature requirements of denitration device reactor. At this time, the flue gas temperature at $\mathrm{SCR}$ inlet is $300.145^{\circ} \mathrm{C}$, the flue gas temperature of boiler is $120.054^{\circ} \mathrm{C}$, and the boiler efficiency is $93.3186 \%$.

It can be seen from Table 4 that after adopting the three schemes for transformation, there is no significant difference between the superheated steam outlet temperature and the reheated steam outlet temperature before the transformation, so the steam quality will not be affected. The changes of flue gas temperature and thermal efficiency of three kinds of wide load denitration transformation schemes and before transformation are shown in Figure 5. After the transformation of scheme $\mathrm{A}$ and scheme $\mathrm{C}$, the exhaust gas temperature increased by about $8^{\circ} \mathrm{C}$ compared with that before the transformation, and the boiler efficiency was lower by about $0.4 \%$. Scheme B exhaust gas temperature and boiler efficiency are basically the same as before the transformation. The results show 
Table 4. Comparison of calculation data between the three transformation schemes and the thermal system before transformation.

\begin{tabular}{ccccc}
\hline Item & $\begin{array}{c}\text { Before } \\
\text { transformation }\end{array}$ & Plan A & Plan B & Plan C \\
\hline $\begin{array}{c}\text { Working fluid temperature at } \\
\text { the outlet of the final reheater }\left({ }^{\circ} \mathrm{C}\right)\end{array}$ & 481.03 & 483.35 & 480.91 & 482.36 \\
$\begin{array}{c}\text { Working fluid temperature at } \\
\text { the outlet of the final superheater }\left({ }^{\circ} \mathrm{C}\right)\end{array}$ & 511.52 & 514.13 & 511.56 & 509.99 \\
$\mathrm{SCR}$ inlet flue gas temperature $\left({ }^{\circ} \mathrm{C}\right)$ & 279.76 & 301.15 & 302.62 & 300.15 \\
$\quad \begin{array}{c}\text { exhaust temperature }\left({ }^{\circ} \mathrm{C}\right) \\
\text { Boiler efficiency }(\%)\end{array}$ & 112.73 & 120.42 & 112.83 & 120.05 \\
$\begin{array}{c}\text { Working fluid temperature at } \\
\text { the outlet of the economizer }\left({ }^{\circ} \mathrm{C}\right)\end{array}$ & 93.72 & 93.29 & 93.72 & 93.32 \\
\hline
\end{tabular}

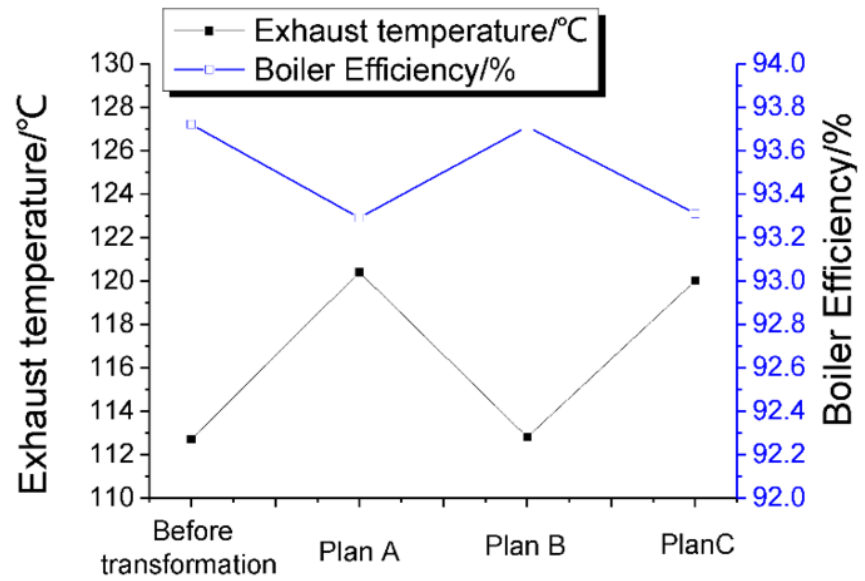

Figure 5. Changes of flue gas temperature and boiler thermal efficiency before and after renovation.

that the effects of the three transformation schemes on the thermal efficiency of the unit are all within an acceptable range, among which option B has almost no effect on the thermal efficiency of the unit.

Considering the safety of the unit, the working pressure of the economizer is $11.6 \mathrm{MPa}$ under $25 \%$ rated load conditions. After calculation and analysis, the saturation temperature of water under this pressure condition is $310.5^{\circ} \mathrm{C}$. Scheme B and Scheme C economizer outlet working fluid temperature is lower than before the transformation, and compared with saturation temperature has a large margin, there is no problem of working fluid boiling in the economizer. The bypass flow of scheme A needs to account for more than $79 \%$ of the total flow to be able to increase the temperature of the flue gas at the inlet of the SCR to above $300^{\circ} \mathrm{C}$. At this time, the working fluid temperature at the outlet of the economizer is $310.026^{\circ} \mathrm{C}$, which is very close to the saturation temperature of the water under this pressure condition. There is not enough under-temperature margin, which can easily cause the working fluid in the economizer to boil, threatening the safe and stable operation of the unit. When the bypass flow is reduced, the temperature of the working fluid in the economizer will decrease, and the temperature of the flue gas at the inlet of the SCR will also decrease. Therefore, plan A cannot meet the requirements of stable operation of the denitrification system under ultra-low load conditions. 
In order to ensure the stable operation of the unit under high load conditions, it is necessary to calculate the thermal system under high load conditions for Scheme B. In this paper, 299.3MW operating conditions are selected for calculation, and the results are shown in Table 5.

Table 5. 299.3MW load thermal system calculation results.

\begin{tabular}{ccc}
\hline Calculation Results & $\begin{array}{c}\text { Flue gas outlet } \\
\text { temperature }\end{array}$ & $\begin{array}{c}\text { Working fluid outlet } \\
\text { temperature }\end{array}$ \\
\hline Partition screen superheater $\left({ }^{\circ} \mathrm{C}\right)$ & 1163.38 & 435.682 \\
Rear screen superheater $\left({ }^{\circ} \mathrm{C}\right)$ & 1048.71 & 515.921 \\
Screen reheater $\left({ }^{\circ} \mathrm{C}\right)$ & 924.078 & 446.527 \\
Final reheater $\left({ }^{\circ} \mathrm{C}\right)$ & 800.182 & 542.575 \\
Final superheater $\left({ }^{\circ} \mathrm{C}\right)$ & 698.343 & 546.984 \\
Horizontal low temperature superheater $\left({ }^{\circ} \mathrm{C}\right)$ & 461.604 & 404.706 \\
Primary economizer $\left({ }^{\circ} \mathrm{C}\right)$ & 412.652 & 287.745 \\
Secondary economizer $\left({ }^{\circ} \mathrm{C}\right)$ & 396.23 & 293.699 \\
Rotary air preheater $\left({ }^{\circ} \mathrm{C}\right)$ & 144.211 & 374.381 \\
SCR inlet flue gas temperature $\left({ }^{\circ} \mathrm{C}\right)$ & 412.65 & - \\
\hline
\end{tabular}

After adopting plan B for transformation, the SCR reactor is arranged between the primary economizer and the secondary economizer. Under high load conditions, the flue gas temperature at the inlet of the $\mathrm{SCR}$ is about $412^{\circ} \mathrm{C}$, which is higher than the maximum operating temperature of the reactor of the denitrification unit, which affects the stable operation of the denitrification unit under high load conditions. Therefore, Option B cannot meet the requirement of stable operation of the denitration system under high load conditions.

In summary, scheme $\mathrm{C}$ is the optimal scheme for the flexibility transformation of wide-load denitration. After the transformation, due to the adjustability of the bypass flue transformation, the boiler efficiency of the unit under high load conditions is not affected, and the boiler efficiency under medium and low load conditions is slightly reduced, up to about $0.4 \%$.

\section{Program Evaluation and Precautions}

\subsection{Case Evaluation}

After the equipment modification according to plan $\mathrm{C}$, the high-temperature flue gas bypass modification during the operation of the unit can be adjusted according to the load situation, so it is only necessary to evaluate the tail flue gas flow rate and the pulverizing system under low load conditions.

(1) Assessment of the impact on the operation of the pulverizing system. After calculation, under $25 \%$ rated load conditions, the flue gas temperature at the inlet of the air preheater is increased, and the temperature of the hot air at the outlet of the air preheater is increased by $19^{\circ} \mathrm{C}$, which is beneficial to increase the drying output of the coal mill. 
(2) Estimation of the change of flue gas flow rate. After the transformation, under $25 \%$ rated load conditions, $17 \%$ of the flue gas needs to be extracted to the bypass flue. At this time, the flue gas flow rate in the main flue is reduced by about $0.2 \mathrm{~m} / \mathrm{s}$. As the flue gas flow rate is slightly reduced, the flue may be more prone to fouling. Technical measures to prevent fouling of the flue should be considered during the implementation of specific renovations.

(3) Economic evaluation of deep peak shaving. Through wide-load denitration technology transformation, the unit can stably participate in deep peak shaving. According to the "Notice of North China Energy Regulatory Bureau on Carrying out Simulation Operation of Inner Mongolia Peak Shaving Auxiliary Service Market", assuming that the average daily peak shaving load of the unit is reduced to $35 \%$ of the rated load, and the average daily peak shaving time is $4 \mathrm{~h}$, based on the Bohai Rim thermal coal price of 570 yuan/ton, the unit's daily peak-shaving power generation cost increases by 909.7 yuan, due to the lack of power generation by peak shaving, the actual profit was reduced by about 840 yuan, and the grid compensation cost was about 21,000 yuan. A rough estimate is that the annual peak shaving income is about 60 million yuan.

\subsection{Matters Needing Attention in the Actual Transformation Process}

(1) The reliability of the flue gas baffle. The flue gas bypass modification program has higher requirements on the reliability of the flue gas damper. If the sealing performance of the flue gas baffle is poor, or the flue gas baffle cannot be closed after being opened, some high-temperature flue gas leaks from the bypass flue under high load conditions and directly enters the SCR device. There is a risk that the flue gas temperature will be higher than the maximum allowable temperature of the catalyst, which may cause fatal damage to the catalyst. If it is not operated at low load for a long time, that is, the baffle door is in a normally closed state, it may cause dust accumulation, jamming and unable to open. In addition, due to the short flue at the SCR interface, the system is prone to problems with the uniformity of flue temperature mixing, and it is easy to appear that the average flue temperature is appropriate, but the local temperature is higher or lower, which will adversely affect the life of the denitration catalyst. Therefore, in the actual implementation of the transformation, the reliability of the flue gas damper plays a vital role in the success of the transformation.

(2) The problem of flue gas temperature deviation. After the boiler economizer is installed with a flue gas bypass, the extracted high-temperature flue gas and the lowtemperature flue gas flowing through the economizer may be insufficiently mixed, resulting in uneven flue gas flow and temperature fields, and large flue temperature deviations. As a result, the local flue gas temperature in the low-load denitration zone of the unit is lower than $300^{\circ} \mathrm{C}$, which deviates from the optimal reaction temperature of the denitration catalyst, reduces the catalyst activity, reduces the denitrification efficiency, and increases the ammonia escape rate. Therefore, in the process of reforming the flue gas bypass scheme, attention should be paid to the uniformity of the flue gas field. A deflector can be installed in the flue to make the high-temperature flue gas and the low-temperature flue gas fully mixed.

(3) The pressure difference of the air preheater increases. If the problems of flue gas flow field and temperature field are not fully considered during the transformation, a large deviation of the flue gas temperature may occur after the transformation, which leads to an increase in the ammonia escape rate of the denitration system. Unreacted 
liquid ammonia reacts with $\mathrm{SO} 3$ and water generated during the combustion of the boiler to form NH4HSO4. NH4HSO4 has a dew point of $147^{\circ} \mathrm{C}$, which is concentrated on the surface of an object in the form of liquid or dispersed in the flue gas in the form of droplets. Liquid NH4HSO4 is a very corrosive and viscous substance, which easily adheres to fly ash in the flue gas. As the temperature of the cold end of the air preheater is lower than $147^{\circ} \mathrm{C}$, the liquid NH4HSO4 will adhere to the heating surface of the air preheater, which will not only cause corrosion to the cold end components, but also further adhere to the fly ash, which can not be removed by soot blowing through the air preheater. As a result, the pressure difference of the air preheater gradually increases, which may eventually cause the unit to have to be shut down for flushing or furnace shutdown on one side, which seriously threatens the safe and stable operation of the unit. In order to avoid the problem of increasing the pressure difference of the air preheater, the problem of flue gas mixing should be fully considered during the transformation process [5].

\section{Conclusions}

In order to solve the problem of low SCR inlet flue gas temperature during the operation of a $300 \mathrm{MW}$ unit, the unit has deep peak regulation capability and can stably put the SCR denitrification device into operation under ultra-low load conditions. Three solutions are proposed, and the thermal system calculation and comparison analysis are carried out on the three solutions respectively. Finally, the program $\mathrm{C}$ flue gas bypass modification program is selected for wide-load denitrification modification. After the transformation, under ultra-low load conditions, the inlet flue gas temperature of the SCR can be increased to over $300^{\circ} \mathrm{C}$ through bypass flue adjustment, and at the same time, the safety and economy of the unit under high load conditions will not be affected. In addition, after the transformation of Plan $\mathrm{C}$, the possible impact of the daily production and operation of the unit and the economic benefits of participating in deep peak shaving were carefully evaluated, and the key issues that need to be paid attention to during the transformation were discussed.

\section{Acknowledgements}

This research was financially supported by the Inner Mongolia Electric Science Research Institute 2020 youth science and technology project NO. 510241200018.

\section{References}

[1] X W Zhou, Q J Hua, A Wang, W Xu, H Chen. Study on optimization and transformation technology of SCR system in deep peak-shaving boiler for 1000MW units [J]. Power System Engineering, 2020, 36 (1): 57-60.

[2] L L Liu, Y Chen, X F Li, M Kuang, Z H Wang, J H Zhou and K F Cen. Thermodynamic calculation of various heating surface adjustments of a $600 \mathrm{MW}$ boiler: Used to reduce the exhaust gas temperature [J]. Energy Engineering, 2015, (5): 57-62.

[3] L L Liu, X F Li, Y Chen, M Kuang, Z H Wang, J H Zhou, Cen K F Cen. Thermodynamic calculation for the tail heating surface optimization used to reduce the exhaust gas temperature of a $600 \mathrm{MW}$ sub-critical boiler [J]. Boiler Technology, 2017, 48 (1): 1-5. 
[4] Q Miao. Progress and prospects of denitration technology [J]. Clean Coal Technology, 2017, 23 (2): 1219.

[5] X P Zheng, S X Li, J Guo, Z L Liu, D H Yuan. Analysis and treatment of air pre-heater clogging in CFB boiler [J]. Inner Mongolia Electric Power, 2019, 37 (5):29-32. 